\section{Meta-analysis of factors related to health services that predict treatment default by tuberculosis patients}

\author{
Metanálise de fatores relacionados aos serviços de \\ saúde que predizem o abandono de tratamento \\ por pacientes com tuberculose
}

\author{
${ }^{1}$ Instituto de Pesquisa \\ Clínica Evandro Chagas, \\ Fundação Oswaldo Cruz, \\ Rio de Janeiro, Brasil. \\ 2 Instituto de Medicina \\ Social, Universidade do \\ Estado do Rio de Janeiro, \\ Rio de Janeiro, Brasil. \\ ${ }^{3}$ Centro de Referência \\ Professor Helio Fraga, \\ Rio de Janeiro, Brasil. \\ Correspondence \\ P. E. A. A. Brasil \\ Departamento de Doenças \\ Infecciosas, Instituto de \\ Pesquisa Clínica Evandro \\ Chagas, Fundação Oswaldo \\ Cruz. \\ Av. Brasil 4365, Rio de \\ Janeiro, $R J$ \\ 21045-900, Brasil. \\ pemmanuel@ipec.fiocruz.br
}

\begin{abstract}
The identification of factors that predict tuberculosis (TB) treatment default can help control this problem. The current study used a systematic review to investigate associations between $T B$ treatment default and previously studied factors related to health services. Abstracts were searched in the MEDLINE and LILACS databases and in the bibliography of the full texts under evaluation. Studies were included if TB treatment default was evaluated by comparing two or more groups and data could be extracted. A total of 41 studies were included for combining data. It was possible to combine five exposures: "difficult access to health services"; "need for hospitalization"; "training or support for adherence"; "delay in initiating treatment"; "long wait before medical attendance". "Difficult access to health services", "training or support for adherence", and "need for hospitalization" were associated with TB treatment default. All exposures demonstrated heterogeneity, which was only explained in one. Publication bias was only detected for one exposure.
\end{abstract}

Tuberculosis; Patient Dropouts; Meta-Analysis
Pedro Emmanuel Alvarenga Americano do Brasil 1,2

José Ueleres Braga 2,3

\section{Introduction}

Tuberculosis (TB) is a highly prevalent disease in the poorest regions of the world and a reemerging problem in the developed countries 1. Tuberculosis was recognized as a major worldwide emergency in 1993 2. The main TB control strategy includes early diagnosis and treatment of individuals with the disease. This strategy allows for control of the sources of infection and blocking the disease 1,2 . The standard TB treatment regimen is effective but is not applied efficiently in most countries. Worldwide, TB treatment default has been estimated at between $1 \%$ and $20 \% 1$, but the rate is as high as $60 \%, 70 \%$, and even $80 \%$ in selected populations $3,4,5,6,7$.

Considering this situation, since the 1990s the World Health Organization (WHO) has recommended the DOTS strategy (Directly Observed Treatment, Short Course) to be used by all countries as a means to control TB. Although WHO considers direct therapy observation the main key of treatment success, some authors also emphasize that other important features involving lack of patient care by the health team are also related to patient default 8,9 .

Different strategies to improve compliance (or to reduce default) have been investigated, and different effects on treatment default have been estimated for TB 10,11 and other diseases 12,13. Studies on the effects of incentives (cash, bus tokens, etc.) on TB treatment default have shown 
the benefits of these approaches 10,14. Some systematic reviews have demonstrated the benefits of these interventions (mainly incentives) in adherence to treatment regimens for different diseases 12,13,15. Most of these interventions are considered to be outside the routine activities of health services, but the performance of routine surveillance and control measures appears to be a core feature that is crucial to improve TB patient compliance.

Analysis of causes of TB treatment default shows that patient-related factors are the most frequently evaluated. Health service characteristics have received insufficient attention. Causes of default are likely to be highly heterogeneous, considering different cultures, locations, and populations, disease severity, adverse effects of treatment, and health systems. Such sources of heterogeneity can even influence the results of clinical trials. A systematic review of BCG vaccine clinical trials showed that the latitude of the study location influenced the vaccine's effect 16 . The authors concluded that prevalence of TB infection in different locations could influence the effect of the vaccine.

We conducted a review to identify risk factors for TB treatment default as published in the international literature. The review showed that the most frequently investigated risk factors for TB treatment default could be grouped as: (1) individual patient profile; (2) clinical status or therapy; and (3) health services characteristics. For classification of these exposures, the number of studies arranged in decreasing order were: age, gender, alcoholism, HIV/AIDS, illicit drug use, foreign nationality, illiteracy (or low schooling), unemployment, homelessness, race, income, tobacco use, imprisonment, family support, trust in treatment effectiveness, diabetes, and profession in the patient-related group of exposures; TB clinical manifestations (pulmonary or extrapulmonary), retreatment, positive sputum smear (acid-fast bacillus), prior TB treatment default, short-course therapy, adverse effects of therapy, drug resistance, disease severity, use of steroid therapy, TB case contact, and positive culture in the group related to clinical status or therapy; directly observed treatment, difficult access to health services, incentives (financial or other), "need for hospitalization", "training or support for adherence", "delay in initiating treatment", and "long wait before medical attendance" in the group related to health services.

Given the lack of a summary of current knowledge, this paper specifically addresses the latter group of risk factors: health services characteristics. The evaluation of factors strongly associated with TB treatment default should allow the development of better TB control strategies or optimization of existing strategies.

This study thus aims to identify health services factors associated with TB treatment default and to evaluate the heterogeneity and publication bias of each exposure investigated.

\section{Methods}

Two remote databases were used to search for references: MEDLINE (PubMed) and LILACS. The search strategies were constructed according to recommendations found in the literature and based on characteristics such as sensitivity and precision 17. In MEDLINE, references were collected from July 21, 2004, to July 30, 2004, with the following strategy: (tuberculosis[Text] OR "tuberculosis" [MeSH Terms] OR "Antitubercular Agents/ therapeutic use"[MeSH]) AND ("Patient Dropouts/ statistics and numerical data"[MeSH] OR "Patient Compliance/statisticsandnumericaldata" [MeSH] OR adherence[Text] OR Default ${ }^{*}[$ Text]). This strategy was adapted to the LILACS database in Portuguese and English and used as follows: (([] (([] ((ctubercul\$)) or ([MH] “TUBERCULOSE”) or ([MH] "ANTITUBERCULOSOS") or ([MH] ("antibióticos antituberculose")))) and ([] (([MH]“DESISTENCIA DO PACIENTE”) or ([MH] "PARTICIPACAO DO PACIENTE") or ([MH]"RECUSA DO PACIENTE AO TRATAMENTO”) or ([MH] “COOPERACAO DO PACIENTE”) or ([] (adesao)) or ([] (aderencia)) or ([] (abandono $)))))$ ) or ([] (([] $((($ tuberculo\$)) or ([MH]"TUBERCULOSIS") or ([MH] ("antibiotics, antitubercular")) or ([MH] ("antitubercular agents")))) and ([] (([MH] ("treatment refusal")) or ([MH] ("patient compliance")) or ([MH] ("patient dropouts")) or ([MH] ("patient participation")) or ([] (adherence)) or ([] (default\$)) or ([] (compliance)())))) [Words].

The original articles found up to this point were used to obtain bibliographical citations for other research not listed in the electronic databases. No hand search was performed to find original articles, nor were authors contacted regarding incomplete data because these strategies were believed to require excessive labor in relation to the expected results. It was not possible to conduct the search strategy in EMBASE, and other databases were not consulted because they were not considered promising in terms of increasing relevant sources of data.

Two blinded reviewers evaluated the abstracts and full texts and performed data extraction. Abstracts were classified as eligible for full text evaluation if the specified objective was to: (i) identify possible associations between any 
characteristic and TB treatment default (or compliance), (ii) predict TB treatment default by any factor, (iii) investigate relations between risk factors and TB treatment default, or (iv) calculate frequencies or measures of associations with $\mathrm{TB}$ treatment default (or compliance). Abstracts that partially met some of the above-mentioned criteria (objective not clear in the abstract) or were classified differently by the two reviewers were included. Articles that used mainly qualitative methods but also met the criteria were included for full text evaluation.

The full text articles were considered eligible for data extraction if they: (a) were based on original research; (b) included a quantitative analysis; (c) had group comparisons (or compared subgroups) and measures of association were calculated or could be calculated; and (d) had all data available. Also included were articles that studied factors related to TB prophylaxis. Articles that only presented summaries of meetings or congresses were excluded. During this process the reviewers convened to resolve disagreements on abstracts and full text evaluation and extracted data.

No restrictions due to different populations (e.g., children, HIV+ individuals, miners, indigenous peoples, prison inmates, etc.) were made in selecting the abstracts or full text articles. All study designs were initially included, but during the full text evaluation only four designs were selected: cohort, intervention, case-control, and survey.

Abstracts in English, Spanish, and Portuguese were evaluated. Full texts were searched in all languages if the abstracts were selected for full text evaluation. The reviewers read full texts in English, Spanish, and Portuguese, and texts in French and Japanese were translated into Portuguese for evaluation and data extraction.

The original texts that were evaluated presented different definitions of the outcome (TB treatment default) such as: (a) a patient that missed medical appointments or therapy for at least 60 days; (b) use of doses lower than prescribed (e.g., 85\%); (c) incomplete number of tablets consumed by the end of treatment time; (d) incomplete duration of treatment (e.g., six months); and (e) no definition of treatment default. All definitions were included and fitted as a covariate in meta-regression to explain heterogeneity.

In the current article, we excluded the original studies that did not show the result of exposures that could be grouped as "related to health services". Exposures grouped here were: (a) difficult access to health care (time or distance to health units); (b) "need for hospitalization"; (c) train- ing for adherence (peer training for adherence, reception groups, counseling by health professionals); (d) delay in initiating treatment (time between diagnosis and beginning of treatment); and (e) waiting time before medical attendance. DOTS and incentives (cash, bus tokens, etc.) as strategies to improve compliance had been studied in previous systematic reviews 10,11 and were excluded.

Exposures were considered as defined by the authors of the original articles. Most of the original articles either did not define the exposure or the reviewers decided that different proxies were being used to express the same idea. The quality of this aspect of data collection may have been compromised because most of the studies used secondary data.

Specific forms were designed for data extraction. For each study design, a form was developed considering the data specificity. Four models were then tested until a final model could be used for each design: (1) cohort, before and later, quasi-experiments; (2) interventions; (3) casecontrol; and (4) surveys.

Data were keyed in twice by two independent processors using the free-domain software Epidata (Epidata Association, Odense, Denmark). The two data files were compared, and discrepancies were resolved by consulting the original forms. Data analysis used Stata version 9.1 (Stata Corp., College Station, USA), with user-written extensions specific for meta-analysis. Summary estimates were pooled using the random effects model 18 , and the weight ascribed to each estimate was calculated using the Mantel-Haenszel method. We chose odds ratio (OR) as the measure of association, because most exposures were evaluated through case-control studies. For exposures not investigated by case-control studies, we chose risk ratio. Every pooled estimate for each exposure was stratified by study design.

Publication bias was explored in all exposures with the funnel graph (Begg) and Egger test 19,20.

Heterogeneity was explored with the $\mathrm{I}^{2}$ test 21,22 . We considered $\mathrm{I}^{2}$ values greater than $50 \%$ as indicating presence of heterogeneity. To evaluate possible explanations for heterogeneity, we fitted a linear meta-regression model with some characteristics from the original studies as covariates. The Restricted Maximum Likelihood method with the Knapp \& Hartung test was used 23 to estimate $\mathrm{p}$ values for each covariate.

The covariates evaluated by meta-regression in all the exposures were: specificity of the concept of default (without definition; more than 60 days of treatment interruption or less than $85 \%$ of the prescribed doses); reduction of the exposure 
concept (appropriate, less appropriate, not appropriate, or without information, by consensus among the reviewers); population default rates (continuous - calculated as the weighted arithmetic mean of the default rates for each exposure studied or informed for case-control); place of study (Latin America, North America, Europe, Africa, Asia or Australia, Middle East); number of factors studied in the original studies as possibly associated with default (continuous); considerations of adverse effects (appropriate, less appropriate, not appropriate, or without information, by consensus among the reviewers)l; submission to an IRB or institutional review board (yes, no, or not reported); year of publication (continuous); study design (cohort, intervention, case-control, and survey); and proportion of males in the sample (continuous).

\section{Results}

The abstract search resulted in 808 references. One hundred and twenty eight abstracts were found in LILACS and 680 in MEDLINE (PubMed). Of these, 298 were selected for full text retrieval (51 LILACS and PubMed 247), while eight abstracts were found in both databases. Full texts from 13 of 290 selected abstracts were not found, and four were not included because they were written in languages that we were not able to have translated (one article in Danish, one in Chinese, and two in Dutch). Among the abstracts found by electronic search, 273 were selected for full text evaluation. Another 88 abstracts retrieved by bibliographical citation were also selected. The reviewers finally evaluated 361 full texts of published articles (Figure 1).

After evaluation of these full texts, 169 were excluded from the meta-analysis for the following reasons: 12 were basically qualitative studies, 37 were considered reviews of TB treatment default, and 120 did not meet the data extraction criteria. In 192 original articles evaluated, approximately 100 factors investigated for association with TB treatment default were identified. The majority of these factors could be grouped in the individual patient profile group.

This paper does not address all the risk factors studied in our project, but focuses on health services characteristics. Thus, 131 articles were not considered in this analysis because they did not study any factor that could be grouped as "related to health services". Another 20 were excluded because they studied only DOTS or incentives, which were studied in previous systematic reviews 10,11. The 41 remaining studies were included in this analysis.
Table 1 presents some characteristics of the studies included in this meta-analysis: author, year of publication, country where the research was conducted, study design, definition of TB treatment default (criteria), default rate in the sample or in the base population (in case-control design), number of individuals in the sample, and exposures extracted from original studies.

In Table 1, several cells have no information. The table's data include 22 cohort studies, nine interventions, eight case-controls, and two surveys. Considering the definition of default, the empty cells show that no information was available in $26 \%$ of the studies, and $43 \%$ of the papers did not describe the sample's gender distribution. Of these 41 studies, many documented different categories of age distributions, but only 12 (29\%) documented the average (or median) age of the sample. Only one of the nine interventions and none of the 22 cohort studies recorded the mean follow-up time. Thirty-four of 41 studies failed to specify whether the study had been submitted to an IRB. Two of eight case-control studies failed to document the default rate in the base population.

Six of these studies were performed in United States, six in Brazil, four in Malaysia, three in Ethiopia, two each in Spain, Mexico, Nigeria, Pakistan, and Thailand, and one each in other countries.

As noted earlier, 61 original studies evaluated exposures related to health services characteristics, therefore fewer than the 100 articles on factors related to individual patients. This group also showed many factors that were published in only one article, and it was thus impossible to extract and combine them, namely: cash deposit, strategies for retrieving missing patients (studied in a previous systematic review, but not only for TB treatment) 13, location of health care, blood pressure measurement (yes/no), weight measurement (yes/no), good physician-patient relationship, treatment by professionals trained in TB care, satisfaction with care, and incomplete answers to patients' questions, among many others.

Although this meta-analysis studied exposures using intervention designs, the exposures "need for hospitalization" and "delay in initiating treatment" were classified as observational studies, because these exposures were not experimental and allocation of groups was not random.

We detected an association with TB treatment default in two out of five factors (Table 2), namely "difficult access to health services" and "training or support for adherence". A third exposure, "need for hospitalization", showed an association after analysis of heterogeneity. 


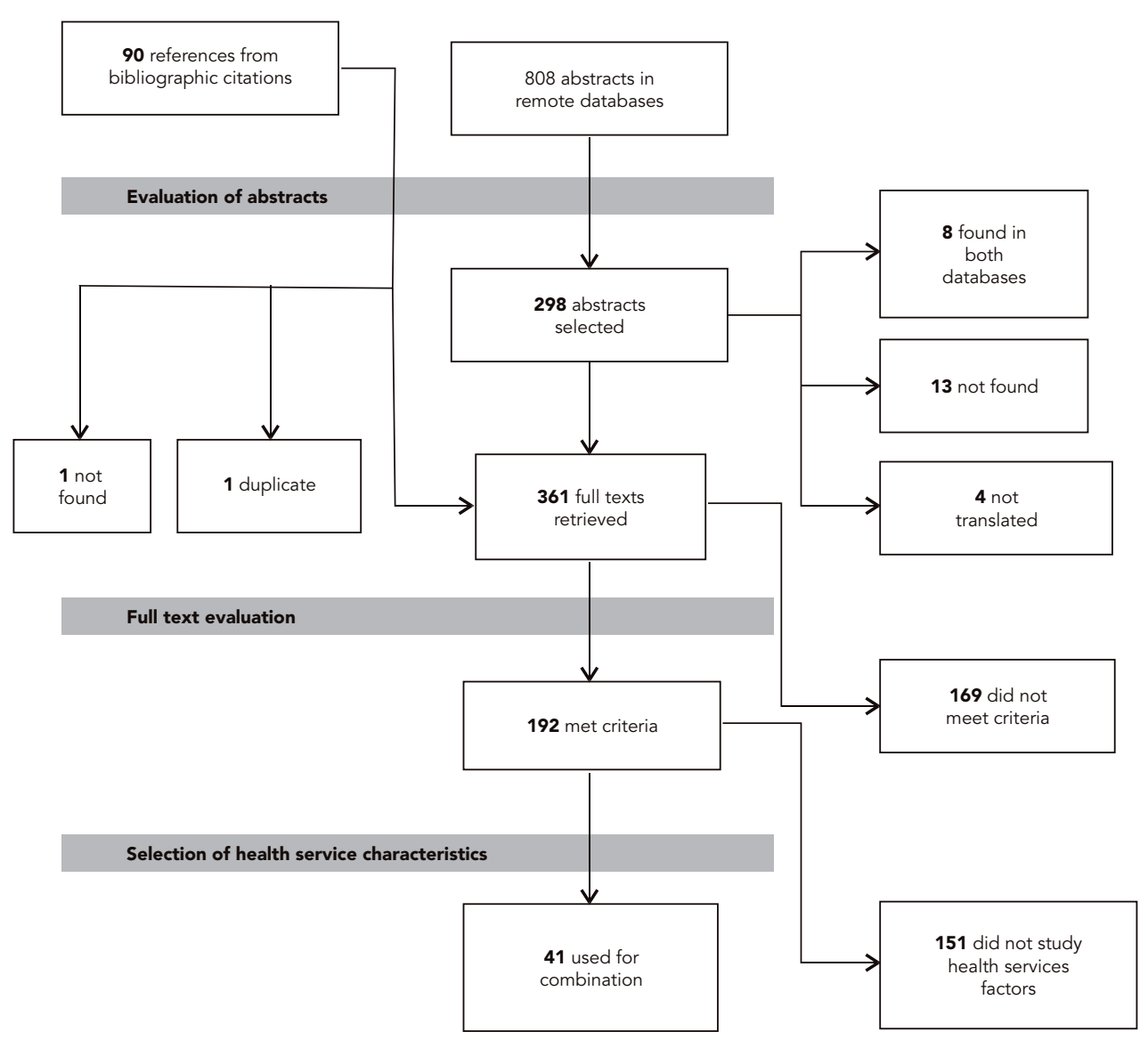

"Difficult access to health services" was studied with several different operational approaches, such as time from patient's residence to the health unit, number of buses taken to reach health unit, living in an area with more versus fewer health units (i.e., urban versus rural areas), and treatment at a local health unit versus in a referral hospital in a different area. A total of 19 studies evaluated this exposure (Table 2). Evaluation of this exposure resulted in $\mathrm{OR}=1.71$. The cohort design studies showed a pooled estimate with a positive association and the highest influence in the total pooled estimate (for all study designs). Estimates from the other designs gave inconclusive results.

One of the cohort studies had a sample of more than 20,000 subjects (Table 1) and showed a positive result (Table 2). Three studies showed associations in the opposite direction (one each, cohort, case-control, and survey), and six showed no evidence of association (four cohorts and two case-controls). The rest of the studies (seven cohorts, two case-controls, and one survey) showed a positive association. However, heterogeneity was high even among those showing a positive association (Table 2).

The exposure "training or support for adherence" was studied in 11 studies, nine of which were trials. Training for adherence mainly involved peer training, defined as an individual with a prior history of TB providing advice to patients currently under treatment. Peers were usually from the same culture, thus facilitating contacts and exchange of experience through communication with a social worker or other health professional who contacted patients reg- 
Table 1

Study characteristics: lead author, year of publication, country, design, default criterion, default rate, proportion of males in sample, sample size, exposures.

\begin{tabular}{|c|c|c|c|c|c|c|c|c|c|c|}
\hline \multirow[t]{2}{*}{ Lead author } & \multirow[t]{2}{*}{ Year } & \multirow[t]{2}{*}{ Country } & \multirow[t]{2}{*}{ Design } & \multicolumn{3}{|c|}{ Default criteria * } & \multirow{2}{*}{$\begin{array}{l}\text { Default } \\
\text { rate (\%) }\end{array}$} & \multirow[t]{2}{*}{ Males (\%) } & \multirow[t]{2}{*}{$\mathbf{N}$} & \multirow[t]{2}{*}{ Risk factor } \\
\hline & & & & $\mathrm{a}$ & b & c & & & & \\
\hline Cassels 32 & 1982 & Tibet & Cohort & 60 & & & 51.54 & & 247 & $\begin{array}{l}\text { Access to health unit; } \\
\text { male gender }\end{array}$ \\
\hline Armstrong 33 & 1984 & Zimbabwe & Cohort & & & & 41.38 & 75.00 & 290 & $\begin{array}{l}\text { Unemployment; extra- } \\
\text { pulmonary TB; need for } \\
\text { hospitalization }\end{array}$ \\
\hline Buri 34 & 1985 & Thailand & Cohort & 120 & & & 13.47 & & 160 & $\begin{array}{l}\text { Alcoholism; access } \\
\text { to health unit }\end{array}$ \\
\hline van der Werf 35 & 1990 & Ghana & Cohort & & & & 49.41 & 65.07 & 569 & $\begin{array}{c}\text { Male gender; } \\
\text { access to health unit }\end{array}$ \\
\hline Irurzun 36 & 1990 & Argentina & Survey & 61 & & & 66.16 & & 195 & $\begin{array}{l}\text { Access to health unit; need } \\
\text { for hospitalization; infor- } \\
\text { mation about TB; delay } \\
\text { in initiating treatment }\end{array}$ \\
\hline Chuah 37 & 1991 & Malaysia & Cohort & & & & 45.85 & & 219 & $\begin{array}{l}\text { Male gender; extra- } \\
\text { pulmonary TB; delay } \\
\text { in initiating treatment; } \\
\text { need for hospitalization }\end{array}$ \\
\hline Barnwell 38 & 1992 & USA & Intervention & & & 100.00 & 60.00 & & 40 & Training for adherence \\
\hline Oviawe 39 & 1993 & Nigeria & Cohort & & & 100.00 & 47.95 & & 146 & Need for hospitalization \\
\hline Moralez 40 & 1993 & Mexico & Cohort & 45 & & & 41.19 & 53.00 & 174 & $\begin{array}{c}\text { Illiteracy; access to } \\
\text { health unit }\end{array}$ \\
\hline Demissie 4 & 1994 & Ethiopia & Case-control & 90 & & & 81.50 & 62.20 & 1,196 & $\begin{array}{c}\text { Unemployment; male } \\
\text { gender; illiteracy; adverse } \\
\text { effects; access to health } \\
\text { unit; information } \\
\text { about TB; cash }\end{array}$ \\
\hline Pilote 41 & 1996 & USA & Intervention & & & & 31.32 & 84.00 & 161 & $\begin{array}{l}\text { Incentives; training } \\
\text { for adherence }\end{array}$ \\
\hline Dick 42 & 1997 & $\begin{array}{l}\text { South } \\
\text { Africa }\end{array}$ & Intervention & & & 75.00 & 14.55 & & 110 & Training for adherence \\
\hline Comolet 43 & 1998 & Madagascar & $\begin{array}{l}\text { Case- } \\
\text { control }\end{array}$ & & & & & 68.45 & 149 & $\begin{array}{l}\text { Alcoholism; male gender; } \\
\text { illiteracy; adverse effects; } \\
\text { access to health unit; } \\
\text { information about TB }\end{array}$ \\
\hline Nuwaha 44 & 1999 & Uganda & Cohort & 60 & & & 36.34 & & 1,495 & $\begin{array}{l}\text { Positive sputum smear; } \\
\text { retreatment; male gender; } \\
\text { treatment duration; } \\
\text { location; need } \\
\text { for hospitalization }\end{array}$ \\
\hline Liefooghe 45 & 1999 & Pakistan & Intervention & 60 & & & 48.95 & 41.85 & 1,019 & $\begin{array}{l}\text { Unemployment; male } \\
\text { gender; training for } \\
\text { adherence; need for } \\
\text { hospitalization; information } \\
\text { about TB; delay in } \\
\text { initiating treatment }\end{array}$ \\
\hline Morrone 46 & 1999 & Brazil & Cohort & & & & 10.67 & 61.17 & 1,226 & $\begin{array}{l}\text { Alcoholism; positive } \\
\text { sputum smear; retreat- } \\
\text { ment; male gender illite- } \\
\text { racy; DOTS; race; delay } \\
\text { in initiating treatment }\end{array}$ \\
\hline
\end{tabular}

(continues) 


\begin{tabular}{|c|c|c|c|c|c|c|c|c|c|c|}
\hline \multirow[t]{2}{*}{ Lead author } & \multirow[t]{2}{*}{ Year } & \multirow[t]{2}{*}{ Country } & \multirow[t]{2}{*}{ Design } & \multicolumn{3}{|c|}{ Default criteria * } & \multirow{2}{*}{$\begin{array}{l}\text { Default } \\
\text { rate }(\%)\end{array}$} & \multirow[t]{2}{*}{ Males (\%) } & \multirow[t]{2}{*}{$\mathbf{N}$} & \multirow[t]{2}{*}{ Risk factor } \\
\hline & & & & a & b & c & & & & \\
\hline Liam 47 & 1999 & Malaysia & Cohort & 0 & & & 28.05 & 58.50 & 114 & $\begin{array}{l}\text { Foreign nationality; } \\
\text { unemployment; male } \\
\text { gender; illiteracy; } \\
\text { treatment duration; } \\
\text { need for hospitalization; } \\
\text { positive culture }\end{array}$ \\
\hline Natal 9 & 1999 & Brazil & Case-control & 60 & & & & & 171 & $\begin{array}{l}\text { Previous default; } \\
\text { alcoholism; positive } \\
\text { sputum smear; } \\
\text { unemployment; } \\
\text { retreatment; } \\
\text { illiteracy; access to } \\
\text { health unit; need } \\
\text { for hospitalization; } \\
\text { information about TB; } \\
\text { long wait before } \\
\text { receiving care }\end{array}$ \\
\hline Borgdorff 48 & 2000 & Netherlands & Cohort & & & & 0.55 & 59.83 & 7,529 & $\begin{array}{l}\text { Previous default; HIV; } \\
\text { foreign nationality; } \\
\text { male gender; extra- } \\
\text { pulmonary TB; access } \\
\text { to health unit; } \\
\text { positive culture }\end{array}$ \\
\hline Al-Hajjaj 49 & 2000 & Saudi Arabia & a Cohort & & & & 44.05 & & 628 & $\begin{array}{l}\text { Unemployment; smoking; } \\
\text { retreatment; male } \\
\text { gender; extra- } \\
\text { pulmonary TB; access } \\
\text { to health unit; } \\
\text { treatment duration; } \\
\text { disease severity }\end{array}$ \\
\hline Ribeiro 50 & 2000 & Brazil & Case-control & 60 & & & 20.00 & 58.00 & 100 & $\begin{array}{l}\text { Alcoholism; positive } \\
\text { sputum smear; HIV; } \\
\text { smoking; male gender; } \\
\text { drug use; extra } \\
\text { pulmonary TB; adverse } \\
\text { effects; training } \\
\text { for adherence }\end{array}$ \\
\hline Piyaworawong 51 & 2001 & Thailand & Cohort & 60 & & & 29.60 & 39.07 & 515 & $\begin{array}{l}\text { Male gender; access to } \\
\text { health unit }\end{array}$ \\
\hline Chaisson 52 & 2001 & USA & Intervention & & & 80.00 & 19.50 & 73.33 & 199 & $\begin{array}{l}\text { DOTS; training for } \\
\text { adherence }\end{array}$ \\
\hline Escobar 53 & 2001 & Brazil & Cohort & 60 & & & 12.33 & & 294 & $\begin{array}{l}\text { Male gender; access to } \\
\text { health unit; need for } \\
\text { hospitalization; } \\
\text { positive culture }\end{array}$ \\
\hline Hoz 54 & 2001 & Spain & Cohort & & & 100.00 & 53.71 & 96.00 & 64 & $\begin{array}{l}\text { Positive sputum smear; } \\
\text { HIV; male gender; } \\
\text { drug use; delay in } \\
\text { initiating treatment; } \\
\text { need for hospitalization }\end{array}$ \\
\hline
\end{tabular}

(continues) 
Table 1 (continued)

\begin{tabular}{|c|c|c|c|c|c|c|c|c|c|c|}
\hline \multirow[t]{2}{*}{ Lead author } & \multirow[t]{2}{*}{ Year } & \multirow[t]{2}{*}{ Country } & \multirow[t]{2}{*}{ Design } & \multicolumn{3}{|c|}{ Default criteria * } & \multirow{2}{*}{$\begin{array}{l}\text { Default } \\
\text { rate }(\%)\end{array}$} & \multirow[t]{2}{*}{ Males (\%) } & \multirow[t]{2}{*}{$\mathbf{N}$} & \multirow[t]{2}{*}{ Risk factor } \\
\hline & & & & a & b & c & & & & \\
\hline Liefhooghe 55 & 2001 & Pakistan & Cohort & 90 & & & 11.30 & 56.00 & 563 & $\begin{array}{l}\text { Illiteracy; lack of family } \\
\text { support; trust in treat- } \\
\text { ment compliance; delay } \\
\text { in initiating treatment }\end{array}$ \\
\hline Morisky 56 & 2001 & USA & Intervention & & & & 20.41 & 51.00 & 377 & $\begin{array}{c}\text { Foreign nationality; lack of } \\
\text { family support; training } \\
\text { for adherence; race }\end{array}$ \\
\hline Naing 57 & 2001 & Malaysia & Case-control & & & 75.00 & 31.00 & & 390 & $\begin{array}{l}\text { Alcoholism; positive } \\
\text { sputum smear; } \\
\text { HIV; smoking; } \\
\text { retreatment; male } \\
\text { gender; drug use; } \\
\text { illiteracy; extra-pulmonary } \\
\text { TB; DOTS; adverse } \\
\text { effects; access to } \\
\text { health unit; location; } \\
\text { housewife; information } \\
\text { about TB; income; } \\
\text { long wait before } \\
\text { receiving care; } \\
\text { disease severity }\end{array}$ \\
\hline White 58 & 2002 & USA & Intervention & 30 & & 100.00 & 51.56 & & 62 & $\begin{array}{l}\text { Incentives; training for } \\
\text { adherence }\end{array}$ \\
\hline Rabahi 59 & 2002 & Brazil & Cohort & 60 & & & 30.27 & 67.40 & 453 & $\begin{array}{l}\text { Alcoholism; positive } \\
\text { sputum smear; } \\
\text { unemployment; HIV; } \\
\text { retreatment; male } \\
\text { gender; adverse } \\
\text { effects; need for } \\
\text { hospitalization; race }\end{array}$ \\
\hline Tekle 60 & 2002 & Ethiopia & Case-control & 90 & & & 11.30 & 55.50 & 228 & $\begin{array}{l}\text { Unemployment; illiteracy; } \\
\text { lack of family support; } \\
\text { adverse effects; access } \\
\text { to health unit; } \\
\text { information about } \\
\text { TB; income }\end{array}$ \\
\hline O'Boyle 61 & 2002 & Malaysia & Case-control & & & & 10.00 & & 86 & $\begin{array}{l}\text { Foreign nationality; } \\
\text { unemployment; male } \\
\text { gender; adverse } \\
\text { effects; need for } \\
\text { hospitalization }\end{array}$ \\
\hline Hovell 62 & 2003 & $\begin{array}{l}\text { USA + } \\
\text { Mexico }\end{array}$ & Intervention & & 180 & 66.60 & 58.08 & 55.60 & 188 & Training for adherence \\
\hline Nyieirenda 63 & 2003 & Malawi & Cohort & 60 & & & 13.34 & & 3,298 & $\begin{array}{l}\text { Extra- pulmonary TB; } \\
\text { access to health unit }\end{array}$ \\
\hline Buu 64 & 2003 & Vietnam & Survey & 60 & & & 8.29 & 70.50 & 4,208 & Access to health unit \\
\hline El-Sony 65 & 2003 & Sudan & Cohort & 60 & & & 15.35 & 59.40 & 20,758 & Access to health unit \\
\hline Alvarez-Gordillo 66 & 2003 & Mexico & Intervention & 60 & & 75.00 & 3.45 & & 87 & Training for adherence \\
\hline Demissie 67 & 2003 & Ethiopia & Cohort & & & & 32.75 & & 128 & $\begin{array}{l}\text { Male gender; illiteracy; } \\
\text { training for adherence; } \\
\text { access to health } \\
\text { unit; profession }\end{array}$ \\
\hline
\end{tabular}

(continues) 


\begin{tabular}{|c|c|c|c|c|c|c|c|c|c|c|}
\hline \multirow[t]{2}{*}{ Lead author } & \multirow[t]{2}{*}{ Year } & \multirow[t]{2}{*}{ Country } & \multirow[t]{2}{*}{ Design } & \multicolumn{3}{|c|}{ Default criteria * } & \multirow{2}{*}{$\begin{array}{l}\text { Default } \\
\text { rate (\%) }\end{array}$} & \multirow[t]{2}{*}{ Males (\%) } & \multirow[t]{2}{*}{$\mathbf{N}$} & \multirow[t]{2}{*}{ Risk factor } \\
\hline & & & & a & b & c & & & & \\
\hline Salami 68 & 2003 & Nigeria & Cohort & 90 & & & 50.21 & 52.00 & 1,530 & $\begin{array}{l}\text { Previous default; } \\
\text { alcoholism; } \\
\text { unemployment; HIV; } \\
\text { smoking; male gender; } \\
\text { illiteracy; access to } \\
\text { health unit; need } \\
\text { for hospitalization }\end{array}$ \\
\hline Cayla 69 & 2004 & Spain & Cohort & 60 & & & 4.69 & 64.50 & 1,291 & $\begin{array}{l}\text { Foreign nationality; HIV; } \\
\text { male gender; drug use; } \\
\text { DOTS; delay in initiating } \\
\text { treatment; homelessness; } \\
\text { need for hospitalization }\end{array}$ \\
\hline Salles 30 & 2004 & Brazil & Case-control & 60 & & & 20.20 & & 163 & $\begin{array}{c}\text { Alcoholism; } \\
\text { unemployment; HIV; } \\
\text { male gender; race; } \\
\text { income; long wait } \\
\text { before receiving care }\end{array}$ \\
\hline
\end{tabular}

* Default criteria: (a) minimum number of days since last appointment; (b) minimum number of doses to complete treatment; and (c) minimum number of doses taken of total prescribed ratio to complete treatment).

ularly to encourage treatment compliance. Only instructions regarding compliance were included (but not teaching about the disease). Some studies also focused on concurrent interventions (e.g., different amounts of incentives) that could not be separated from this exposure evaluation. The pooled estimate from the trials, the estimate from the single cohort, and the single case-control showed similar OR values, which were similar to the overall estimate $(\mathrm{OR}=0.48)$. Publication bias was not detected, but high, unexplained heterogeneity was present due primarily to the trials (Table 2). Even though the heterogeneity was not explained, almost all the studies showed results in the same direction (Figure 2), indicating that this exposure results in protection against $\mathrm{TB}$ treatment default.

The exposure "need for hospitalization" was investigated in 14 studies (Figure 3). Hospital admission for supervised treatment alone was not defined as hospitalization. The overall estimate did not show an association with TB treatment default. Among the study design groups, only the pooled OR from the cohorts did not show associations $(\mathrm{OR}=1.29)$. The pooled estimate from casecontrols $(\mathrm{OR}=2.27)$ and the single survey $(\mathrm{OR}=$ 2.13) did show associations, and the single intervention showed a protective association $(\mathrm{OR}=$ 0.48). Publication bias (Egger p value of 0.013 ) and heterogeneity were detected $\left(\mathrm{I}^{2}=86.2 \%\right)$.
However, this was the only exposure in which heterogeneity was partially explained.

Heterogeneity was not detected in the group of studies conducted in Latin America (OR = 2.46 [1.74-3.47]; $\mathrm{I}^{2}=0.0 \%$ ) or those in Europe $\left(\mathrm{OR}=1.46[0.45-4.76] ; \mathrm{I}^{2}=31.0 \%\right)$. In the other two categories (Africa and Asia \& Australia), the heterogeneity remained $(\mathrm{OR}=0.81[0.53-1.23]$, $\mathrm{I}^{2}=89.0 \%$; OR $=1.26[0.48-3.29], \mathrm{I}^{2}=80.5 \%$ respectively). Publication bias was not found in any category. In two of five categories there were not enough studies to calculate the publication bias statistics.

"Delay in initiating treatment" and "long wait before medical attendance" (investigated in four and three studies, respectively) were measured as differences in time between the various studies. The two exposures were considered indicators of how health units deal with the number of patients seeking treatment. Neither showed an association with TB treatment default. Heterogeneity was found in both exposures and publication bias only in the latter (Egger $\mathrm{p}$ value 0.005 ) (Table 2).

Publication bias was detected in only two of the five exposures. However, in these two, the number of publications included was low and heterogeneity limits the interpretation of this finding. 
Table 2

Number of subjects, pooled estimates, heterogeneity statistic, and Egger test $p$ value for each exposure and different designs.

\begin{tabular}{|c|c|c|c|c|c|c|c|c|c|}
\hline Exposure & $\mathbf{N}$ & OR & $95 \% \mathrm{Cl}$ & $12(\%)$ & Egger $p$ value & Design (N) & OR & $95 \% \mathrm{Cl}$ & |2 (\%) \\
\hline \multirow[t]{3}{*}{ Difficult access to health service } & 19 & 1.71 & $1.17-2.49$ & 95.7 & 0.305 & Cohort (12) & 1.67 & $1.11-2.50$ & 94.7 \\
\hline & & & & & & Case-control (5) & 2.24 & $0.62-8.03$ & 96.7 \\
\hline & & & & & & Survey (2) & 1.04 & $0.21-5.28$ & 95.6 \\
\hline \multirow[t]{4}{*}{ Need for hospitalization } & 14 & 1.31 & $0.91-1.89$ & 86.2 & 0.013 & Cohort (10) & 1.29 & $0.85-1.97$ & 83.8 \\
\hline & & & & & & Intervention (1) & 0.48 & $0.37-0.62$ & \\
\hline & & & & & & Case-control (2) & 2.27 & $1.27-4.04$ & 0.0 \\
\hline & & & & & & Survey (1) & 2.13 & $1.13-4.00$ & \\
\hline \multirow[t]{3}{*}{ Training or support for adherence } & 11 & 0.48 & $0.29-0.80$ & 81.0 & 0.973 & Cohort (1) & 0.21 & $0.08-0.51$ & \\
\hline & & & & & & Intervention (9) & 0.57 & $0.33-0.99$ & 80.8 \\
\hline & & & & & & Case-control (1) & 0.23 & $0.13-0.69$ & \\
\hline \multirow[t]{3}{*}{ Delay in initiating treatment * } & 4 & 1.12 & $0.92-1.36$ & 58.6 & 0.615 & Cohort (2) & 1.13 & $0.84-1.52$ & 8.1 \\
\hline & & & & & & Intervention (1) & 0.97 & $0.84-1.12$ & \\
\hline & & & & & & Survey (1) & 1.31 & $1.08-1.58$ & \\
\hline $\begin{array}{l}\text { Long wait before medical } \\
\text { attendance }\end{array}$ & 3 & 2.11 & $0.80-5.54$ & 80.4 & 0.005 & Case-control (3) & 2.11 & $0.80-5.54$ & 80.4 \\
\hline
\end{tabular}

* Risk ratio.

Figure 2

Funnel plot (A) and Forest plot (B) of adherence training or support and TB treatment default.

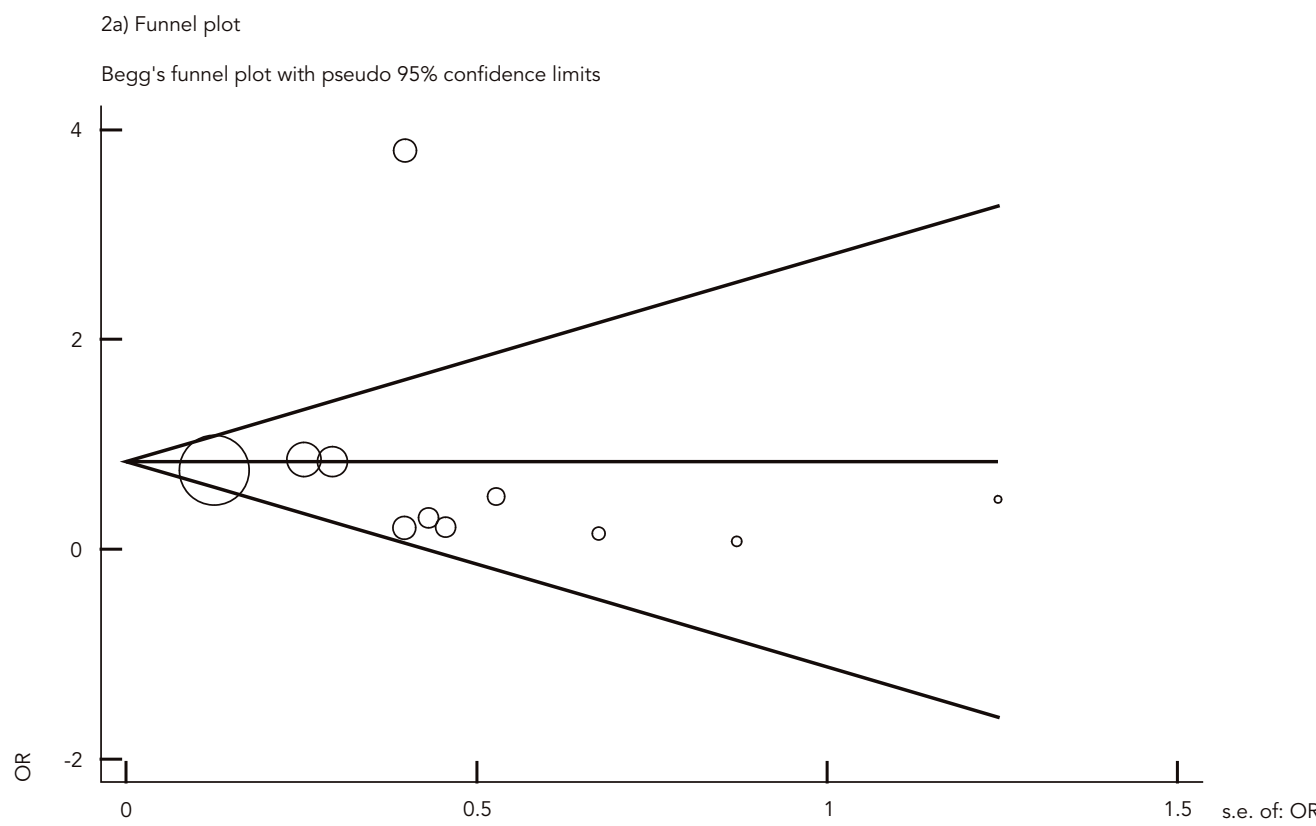

(continues) 


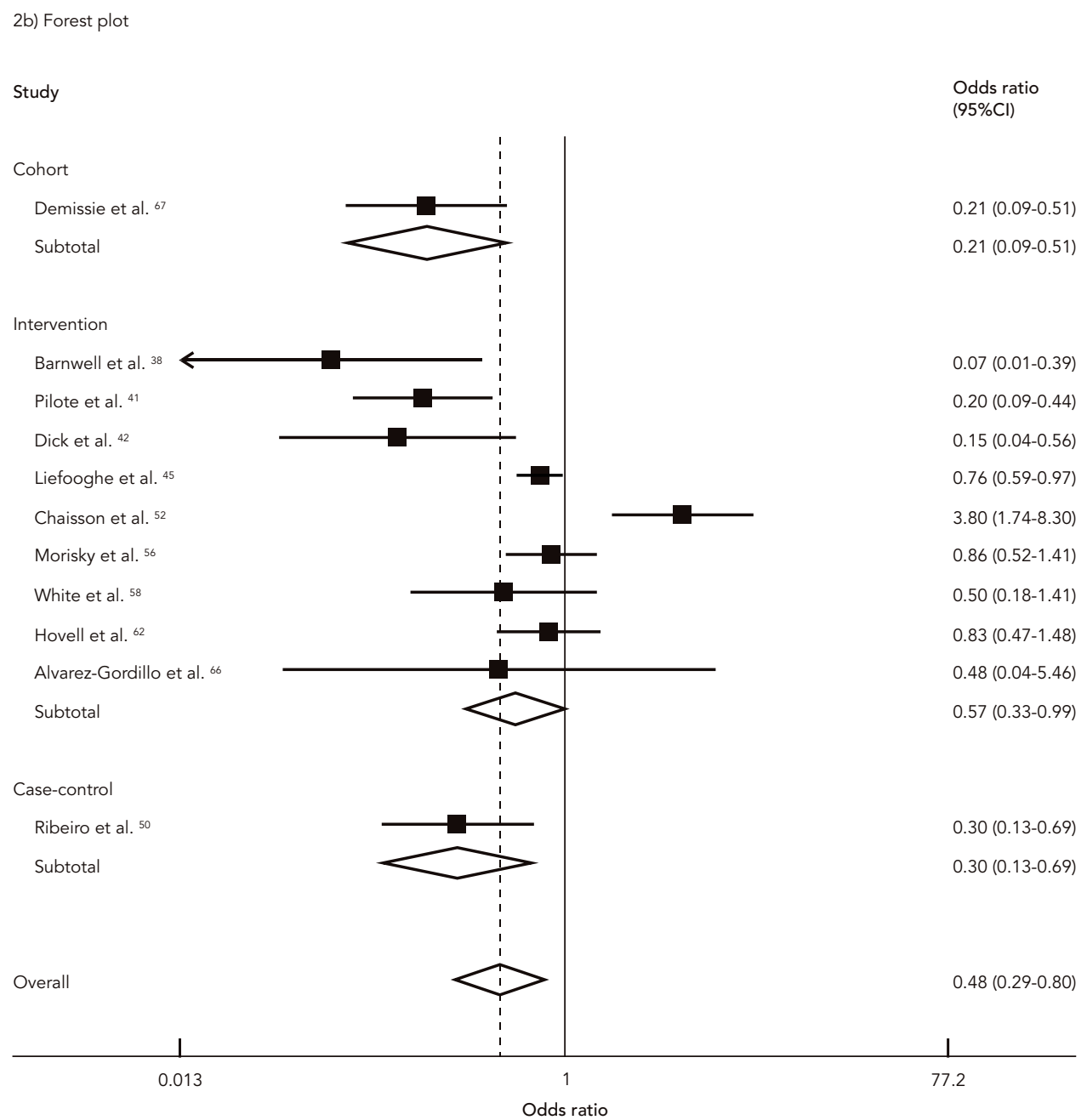

\section{Discussion and conclusion}

A difficult step in analyzing these exposures was deciding which of them could be grouped as health services characteristics. For example, hospitalization could be classified in the clinical status group instead. Patients could presumably be admitted to hospital because they have disseminated TB, i.e., more severe clinical status. However, we decided to include hospitalization in this group because hospitalized patients may have become more ill because the health system was unable either to detect and treat them early or to maintain them in appropriate treatment.

In the literature on meta-analysis methodology, some authors suggest that pooled measures should not be estimated because obser- vational studies are more susceptible to bias 24 . According to other authors, systematic reviews of observational studies should explore heterogeneity and describe different characteristics instead. In fact, the quality of the original study directly interferes in the validity of the pooled estimate. However, there are several exposures that would never be tested as interventions, and therefore observational studies are the best evidence available. Finally, according to many researchers, systematic reviews and meta-analysis of observational studies should be performed, and they are performed as frequently as metaanalysis of clinical trials 24,25 .

Two of five exposures ("training or support for adherence" and "difficult access to health services") have an overall pooled estimate showing as- 
Funnel plot (A) and Forest plot (B) of hospitalization and TB treatment default.

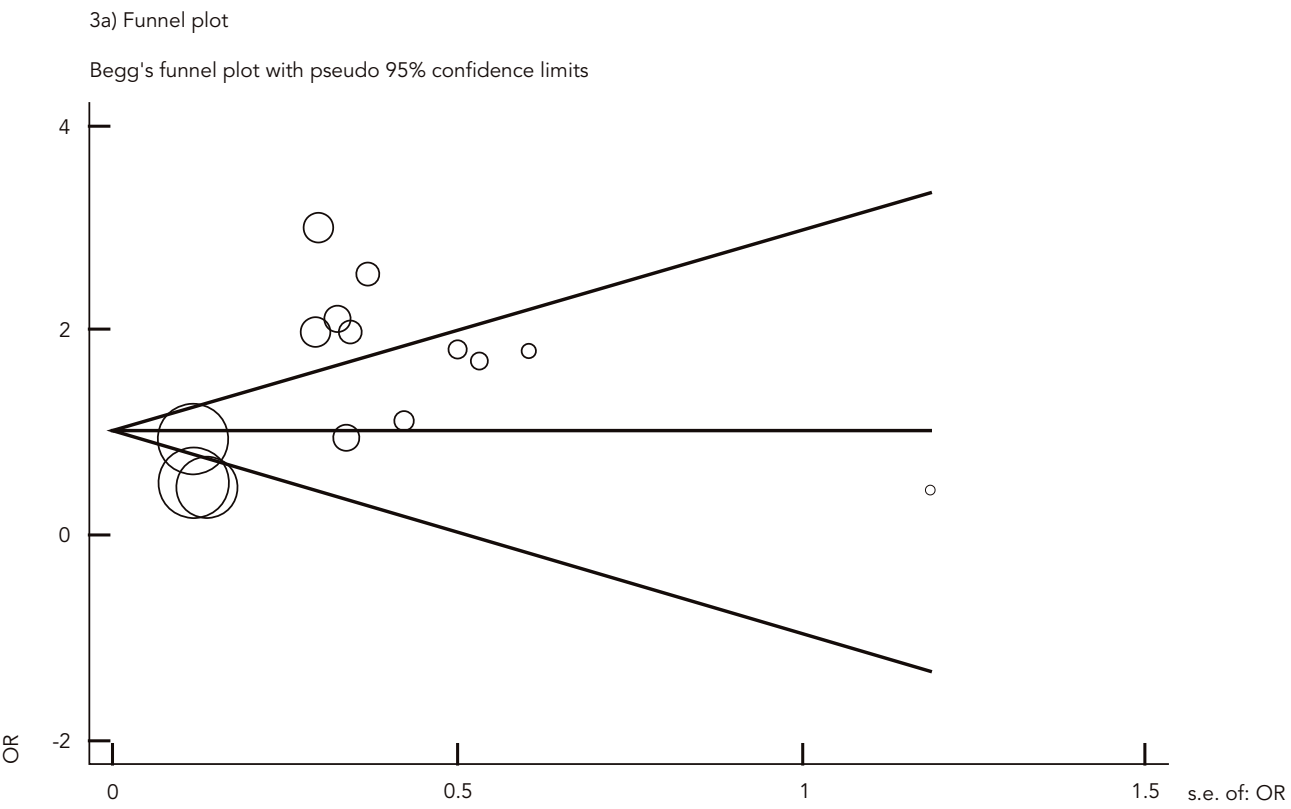

(continues)

sociation with TB treatment default, while a third exposure ("need for hospitalization") showed an association in a particular scenario after exploring heterogeneity. All of the exposures we studied here demonstrated high heterogeneity.

With only one exception, all the studies included as training for adherence showed results in the same direction. That is, even with concurrent interventions in some studies, adherence training could predict treatment compliance even when heterogeneity was detected. One can generally assume that treatment adherence training reduces default by about $50 \%$.

The exposure "difficult access to health services" showed an association with TB treatment default with an overall OR of 1.71 (Table 2). This association indicates that individuals living far from the health units have about 1.71 times the odds of defaulting treatment as compared to those living nearby, but there are studies with results in both directions. In this case, three studies showed protection, six showed no evidence of association with treatment default, and 10 studies showed association with TB treatment default. One cohort study showing an association between difficult access and default had a sample of more 20 thousand subjects, which of course had a strong influence on the pooled estimate.

The exposure "need for hospitalization" was not associated with TB treatment default (Table 2). However, after heterogeneity analysis, the interpretation changed. The studies conducted in Latin America showed a positive association between hospitalization and treatment default, and no heterogeneity was found. In Latin America, TB patients admitted to hospital had a default rate nearly 2.5 times that of individuals not requiring hospitalization. Studies in Europe did not show this association with TB treatment default. Elsewhere, this association appears not to exist, but this cannot be determined categorically because of the observed heterogeneity.

The exposures "delay in initiating treatment" and "long wait before medical attendance" may indicate the same condition: the ability of the unit to meet local demand for TB care. Different health units may have different capacities to meet local demand, and these exposures may thus indicate how well organized and prepared they are to care for TB patients. Here, heterogeneity was not explained. Very few studies were included in these exposures (Table 2). Consid- 


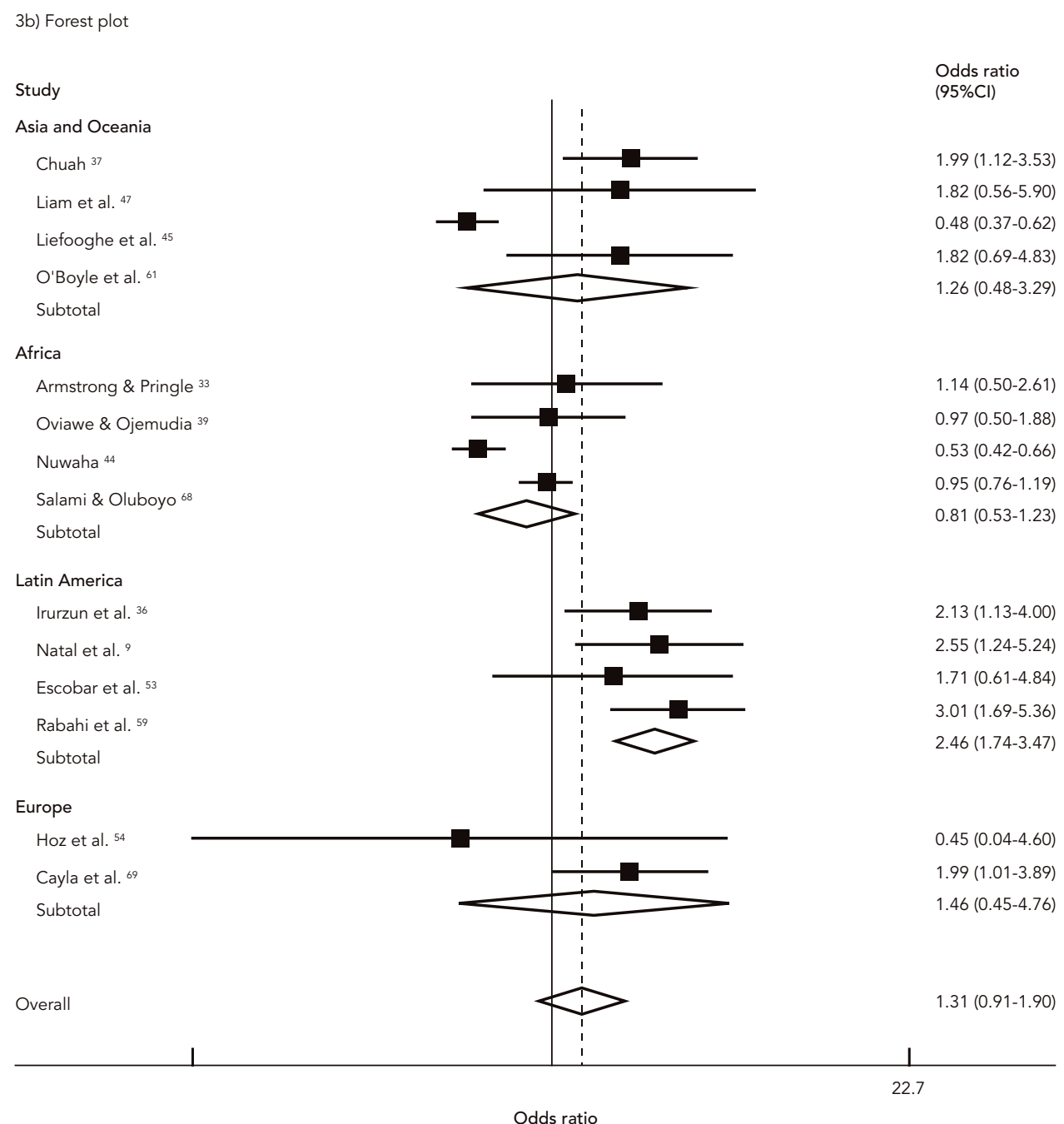

ering "delay in initiating treatment", three of four studies (two cohorts and one intervention) showed no evidence of association, while one (a survey) showed evidence of association. The exposure "long wait before medical attendance" included only three studies. One (a case-control), with the highest influence, showed no evidence of association, while the other two (both casecontrols) showed evidence of association. In the latter exposure, a tendency towards association was observed. However, the relative lack of studies and the fact that the largest study showed no evidence of relationship does not allow for detection of the association between these exposures and TB treatment default.

According to a systematic review published in 199710 and including six trials, other strategies (mainly incentives) had a positive impact, i.e., increasing compliance. Importantly, the author discusses the conceptual and practical differences and in which situations theses strategies could be most beneficial. Most of the strategies could be applied together with those recommended by WHO 26 . However, some health services managers (even without scientific evidence) argue that incentives could create a culture of "professional" patients, who would fail to take the medicines and remain ill intentionally to keep receiving the cash incentives. Therefore, incentives could perpetuate the source of endemic TB behavior in some settings.

In this systematic review there were five exposures with three to 19 studies each, while the systematic reviews conducted by Volmink \& Gar- 
ner 10,11 included only six trials each. The main differences between this systematic review and those published previously were: (a) they included observational studies allowing the inclusion of factors that would be impossible to study in trials and (b) incentives were considered to be an extra effort by health units in most places, while the factors studied here are indicators of routine efforts to provide effective care to patients.

The high level of heterogeneity can be considered an important result and relevant limitation in summarizing information on risk factors for TB treatment default. Indeed, the heterogeneity should correspond in some way to clinical or epidemiological characteristics of different populations or even differences in investigative methods. Unfortunately, we were not able to show any evidence of these relationships. This may indicate that treatment default may not be equal in different locations, cultures, or even health units. If this is true, there is not just one single problem, but rather many problems to be solved regarding TB treatment default.

The heterogeneity frequently found in observational studies may also be explained by other features such as chance, bias (measurement, selection, and confounding), variation in the outcome rate among the unexposed, and effect modification 27 . Therefore, quality evaluation of methodology in observational studies included in meta-analysis is desired but controversial 28,29. There is no way to assure that some, if not many, of the studies have biased results. Bias is a distortion of a truth that is impossible to know with certainty, although clues to these distortions may be perceived. Some of these clues have been discussed here, during analysis of the quality of some basic concepts.

Different theoretical models of treatment default in each investigation may also contribute to heterogeneity. Different factors may have different effects based on population characteristics, locations, clinical aspects, etc. Different locations may even have some population characteristics that would never be found in others, such as caste in India and Nepal. Factors related to health services with strong influence on TB treatment default may also vary in different populations and locations. The same arguments could be applied to health systems in different countries and even different health units in the same city.

Salles et al. 30, using a case-control design, investigated risk factors (related to individual patients and the health care team) for TB treatment default in outpatients at a tertiary teaching hospital (with a multidisciplinary health staff). No individual risk factors (such as HIV infection or alcoholism) were associated with default. How- ever, some factors classified as proxies for health service activities and health staff-patient relations were associated with default.

It thus appears that even when patient characteristics such as smoking or alcoholism could be the most important factors for predicting TB treatment default, such patients might conceivably interrupt treatment because the health services fail to intervene in these problems. In most cases, these types of approaches (intervention other than provision of TB drugs per se) are not considered routine and may require extra effort to deal with such special needs by patients.

Perhaps due to this difficulty to deal with special needs, some countries (e.g., Israel, United Kingdom, and United States) have adopted legal actions (such as detention for treatment) to help control TB. Although controversial, this approach has been used since the 1980s. However, it is usually applied to patients with repeated hospital admissions for TB that have evaded at least once, contrary to medical orders. Some authors 31 argue that less restrictive measures are often more effective than these legal interventions.

As discussed earlier, most risk factors for TB treatment default studied in the literature have been related to individual patient characteristics. Health services characteristics could be more difficult to investigate, for both operational and ethical reasons.

In the current study, in addition to evaluating the magnitude and direction of associations, we have attempted to capture the diversity of approaches to the same problem by different authors in several different locations and times. An issue that merits increased attention by researchers is the choice of methods for data collection and analysis of secondary data and non-concurrent cohorts. Most of the cohorts included here were non-concurrent (using data from medical records or secondary data systematically collected for surveillance).

This type of design raises several concerns and suggests possible limitations, primarily due to information bias. Secondary data are often not valued because the data focus may not coincide with the research objectives. In addition, the researcher may not be aware of all problems in the selection and data collection, and control of important confounders may prove impossible in the analysis.

In studies using secondary data, it is common to see descriptions of surveillance system characteristics in the methods section, rather than in concepts and definitions, selection strategy, data collection strategy, and data analysis. In such cases, studies may present only crude data with no statistical tests. It is very rare to see discussions 
about the limitations of the results, comments about unexpected results, or a more complex analysis such as survival or multivariate analysis.

Of all variables studied to explain heterogeneity with meta-regression in this review, seven are proxies of study quality, two are proxies of epidemiological characteristics, and one is a proxy of clinical characteristics.

The variables assumed to be proxies of study quality were not very good indicators. In the studies that addressed several exposures at the same time, some exposures were considered appropriate, while for others, no information was described. This created difficulty in determining whether exposures were properly defined or classified. As a variable, submission of the study protocol to an institutional review board was expected to have many missing data. Most of the cohorts were non-concurrent, with data collection from medical records or using secondary data. In the 1980s and 90s, submission of research projects involving human beings for IRB approval was not as common as today, nor was it considered as important. For example, even if only trials are considered, up to half did not mention submission to a research ethics committee. Consideration of adverse treatment effects by authors was missing in $77 \%$ of the studies included here. Although we expected some lack of data on adverse effects, this information proved to be missing in more than half of the trials.

As shown above, even the simplest variables commonly used to describe the study sample, such as age and gender, were lacking in most studies. Even though gender was previously assigned to the meta-regression, it was not possible to evaluate this variable because of missing data. Inclusion of gender as a covariate would exclude many studies using regression analysis.
The concept of default is key to this review. Even regarding this single aspect, quality of reporting in the original studies was poor. Two definitions of default were used: days without treatment (56\%) and the proportion of pills taken throughout the prescribed duration of treatment (17\%).

Indication of the year or time period when studies were conducted was also not available for all studies. Although there is a difference between the publication year and the time when the studies were conducted, we assume that the year of publication could explain some heterogeneity. In addition, it may be that over time, the quality of the research methods improved because of new theoretical and software analytical advances, and therefore the older studies could be more susceptible to bias and heterogeneity.

Interestingly, although heterogeneity was found in all exposures, publication bias was plausible in only two. The suspected publication bias in the exposure "need for hospitalization" did not remain when analyzing the presence of this bias for the categories of the factor that explained heterogeneity. For the exposure "long wait before medical attendance", there were too few studies and this finding could be spurious or influenced by the wide heterogeneity found in these studies. Explanations of publication bias for this exposure were not explored due to the small number of studies included.

We recommend that efforts to investigate reasons for TB treatment default focus on studies with prospective data collection, and that more attention be given to factors potentially related to health services. Data from retrospective studies could be used for theses purposes, but more attention should be given to methodological issues and statistical analysis in these studies. 


\section{Resumo}

Acredita-se que a identificação dos fatores que são preditores do abandono de tratamento de tuberculose contribuiria para o seu controle. Este trabalho combinou, por meio de uma revisão sistemática, medidas de associação entre abandono do tratamento de tuberculose e de fatores relacionados com os serviços de saúde já estudados. Resumos foram procurados nas bases LILACS e MEDLINE e na bibliografia dos textos completos em avaliação. Foram incluídos estudos nos quais foi avaliado o abandono do tratamento através de comparações de dois ou mais grupos e nos quais foi possivel a extração de dados. Ao final, 41 investigações foram incluídas para combinação de dados. Foi possível combinar cinco exposições: "difícil acesso aos serviços de saúde"; "necessidade de hospitalização"; "treinamento ou suporte para adesão"; "demora para o início do tratamento" e "espera longa antes da consulta". "Difícil acesso aos serviços de saúde", "treinamento para adesão" e "necessidade de hospitalização" demonstraram associação com o abandono de tratamento de tuberculose. Todas as exposições apresentaram heterogeneidade e em apenas uma esta foi explicada. Viés de publicação foi encontrado em apenas uma exposição.

Tuberculose; Pacientes Desistentes do Tratamento; $\mathrm{Me}$ tanálise

\section{Contributors}

P. E. A. A. Brasil was responsible for the project development, review, data management, data analysis, and elaboration of the manuscript. J. U. Braga contributed to the project development, review, and elaboration of the manuscript.

\section{Acknowledgments}

The authors wish to thank Dr. Daria Kiselica for the initial revision of the English text. Special thanks go to Dr. Joseney Santos (Brazilian National Tuberculosis Control Program), Dr. Miguel Hijjar (Director of the Prof. Helio Fraga Reference Center), and Dr. Fatima Marinho (Health Surveillance Secretariat, Brazilian Ministry of Health).

\section{References}

1. World Health Organization. Global tuberculosis control: surveillance, planning, financing. Geneva: World Health Organization; 2005.

2. Comitê Assessor para Co-infecção HIV-Tuberculose, Comitê Técnico-Científico de Assessoramento à Tuberculose, Fundação Nacional de Saúde. Tuberculose: guia de vigilância epidemiológica. Brasília: Ministério da Saúde; 2002.

3. Malotte CK, Hollingshead JR, Larro M. Incentives vs. outreach workers for latent tuberculosis treatment in drug users. Am J Prev Med 2001; 20:103-7.

4. Demissie M, Kebede D. Defaulting from tuberculosis treatment at the Addis Abeba Tuberculosis Centre and factors associated with it. Ethiop Med J 1994; 32:97-106.

5. White MC, Tulsky JP, Reilly P, McIntosh HW, Hoynes $\mathrm{TM}$, Goldenson J. A clinical trial of a financial incentive to go to the tuberculosis clinic for isoniazid after release from jail. Int J Tuberc Lung Dis 1998; 2:506-12.
6. Tulsky JP, Pilote L, Hahn JA, Zolopa AJ, Burke M, Chesney M, et al. Adherence to isoniazid prophylaxis in the homeless: a randomized controlled trial. Arch Intern Med 2000; 160:697-702.

7. Matteelli A, Casalini C, Raviglione MC, El-Hamad I, Scolari C, Bombana E, et al. Supervised preventive therapy for latent tuberculosis infection in illegal immigrants in Italy. Am J Respir Crit Care Med 2000; 162:1653-5.

8. Chaulet P. Compliance with anti-tuberculosis chemotherapy in developing countries. Tubercle 1987; 68(2 Suppl):19-24.

9. Natal S, Valente J, Gerhardt G, Pena ML. Modelo para predição para o abandono do tratamento de tuberculose pulmonar. Bol Pneumol Sanit 1999; 7:66-78.

10. Volmink J, Garner P. Systematic review of randomised controlled trials of strategies to promote adherence to tuberculosis treatment. BMJ 1997; 315:1403-6. 
11. Volmink J, Garner P. Directly observed therapy for treating tuberculosis. Cochrane Database Syst Rev 2003; (1):CD003343.

12. Giuffrida A, Torgerson DJ. Should we pay the patient? Review of financial incentives to enhance patient compliance. BMJ 1997; 315:703-7.

13. Macharia WM, Leon G, Rowe BH, Stephenson BJ, Haynes RB. An overview of interventions to improve compliance with appointment keeping for medical services. JAMA 1992; 267:1813-7.

14. Volmink J, Garner P. Interventions for promoting adherence to tuberculosis management. Cochrane Database Syst Rev 2000; (2):CD000010.

15. Healton CG, Messeri P. The effect of video interventions on improving knowledge and treatment compliance in the sexually transmitted disease clinic setting. Lesson for HIV health education. Sex Transm Dis 1993; 20:70-6.

16. Colditz GA, Brewer TF, Berkey CS, Wilson ME, Burdick E, Fineberg HV, et al. Efficacy of BCG vaccine in the prevention of tuberculosis. Meta-analysis of the published literature. JAMA 1994; 271: 698-702.

17. Haynes RB, McKibbon KA, Wilczynski NL, Walter SD, Werre SR. Optimal search strategies for retrieving scientifically strong studies of treatment from Medline: analytical survey. BMJ 2005; 330:1179.

18. DerSimonian R, Laird N. Meta-analysis in clinical trials. Control Clin Trials 1986; 7:177-88.

19. Egger M, Davey-Smith G, Schneider M, Minder C. Bias in meta-analysis detected by a simple, graphical test. BMJ 1997; 315:629-34.

20. Begg CB, Mazumdar M. Operating characteristics of a rank correlation test for publication bias. Biometrics 1994; 50:1088-101.

21. Higgins JP, Thompson SG. Quantifying heterogeneity in a meta-analysis. Stat Med 2002; 21:1539-58.

22. Higgins JPT, Thompson SG, Deeks JJ, Altman DG. Measuring inconsistency in meta-analyses. BMJ 2003; 327:557-60.

23. Knapp G, Hartung J. Improved tests for a random effects meta-regression with a single covariate. Stat Med 2003; 22:2693-710.

24. Egger M, Smith GD, Altman DG. Systematic reviews in health care: meta-analysis in context. $2^{\text {nd }}$ Ed. London: BMJ Books; 2001.

25. Stroup DF, Berlin JA, Morton SC, Olkin I, Williamson GD, Rennie D, et al. Meta-analysis of observational studies in epidemiology: a proposal for reporting. Meta-analysis Of Observational Studies in Epidemiology (MOOSE) group. JAMA 2000; 283:2008-12.

26. World Health Organization. What is DOTS? http:// www.wpro.who.int/sites/stb/dots_definition.htm (accessed on 16/Sep/2006).

27. Dwyer T, Couper D, Walter SD. Sources of heterogeneity in the meta-analysis of observational studies: the example of SIDS and sleeping position. J Clin Epidemiol 2001; 54:440-7.

28. Greenland S. Invited commentary: a critical look at some popular meta-analytic methods. Am J Epidemiol 1994; 140:290-6.

29. Petitti DB. Of babies and bathwater. Am J Epidemiol 1994; 140:779-82.
30. Salles CL, Conde MB, Hofer C, Cunha AJ, Calcada $\mathrm{AL}$, Menezes DF, et al. Defaulting from anti-tuberculosis treatment in a teaching hospital in Rio de Janeiro, Brazil. Int J Tuberc Lung Dis 2004; 8:318-22.

31. Gasner MR, Maw KL, Feldman GE, Fujiwara PI, Frieden TR. The use of legal action in New York City to ensure treatment of tuberculosis. N Engl J Med 1999; 340:359-66.

32. Cassels A, Heineman E, LeClerq S, Gurung PK, Rahut CB. Tuberculosis case-finding in Eastern Nepal. Tubercle 1982; 63:175-85.

33. Armstrong RH, Pringle D. Compliance with antituberculous chemotherapy in Harare City. Cent Afr J Med 1984; 30:144-8.

34. Buri PS, Vathesatogkit P, Charoenpan P, Kiatboonsri S, Buranaratchada S. A clinic model for a better tuberculosis treatment outcome and factors influencing compliance. J Med Assoc Thai 1985; 68: 356-60.

35. van der Werf TS, Dade GK, van der Mark TW. Patient compliance with tuberculosis treatment in Ghana: factors influencing adherence to therapy in a rural service programme. Tubercle 1990; 71:247-52.

36. Irurzun RN, Hasper I, Garcia LE. Retratamiento por tuberculosis, incumplimiento del tratamiento anterior y su relación con el mismo. Rev Argent Tórax 1990; 51:17-30.

37. Chuah SY. Factors associated with poor patient compliance with antituberculosis therapy in Northwest Perak, Malaysia. Tubercle 1991; 72:261-4.

38. Barnwell MD, Chitkara R, Lamberta F. Tuberculosis prevention project. J Natl Med Assoc 1992; 84:1014-8.

39. Oviawe O, Ojemudia E. The problem of non-attendance at a paediatric tuberculosis outpatient clinic. Ann Trop Paediatr 1993; 13:243-7.

40. Moralez EMM, Montes VS, Perez GC, Guerrero EV, Romero CE, Peña JE. Principales causas de abandono del tratamiento contra la tuberculosis pulmonar. Gac Méd Méx 1993; 129:57-62.

41. Pilote L, Tulsky JP, Zolopa AR, Hahn JA, Schecter GF, Moss AR. Tuberculosis prophylaxis in the homeless. A trial to improve adherence to referral. Arch Intern Med 1996; 156:161-5.

42. Dick J, Lombard C. Shared vision: a health education project designed to enhance adherence to anti-tuberculosis treatment. Int J Tuberc Lung Dis 1997; 1:181-6.

43. Comolet TM, Rakotomalala R, Rajaonarioa H. Factors determining compliance with tuberculosis treatment in an urban environment, Tamatave, Madagascar. Int J Tuberc Lung Dis 1998; 2:891-7.

44. Nuwaha F. Control of tuberculosis in Uganda: a tale of two districts. Int J Tuberc Lung Dis 1999; 3: 224-30.

45. Liefooghe R, Suetens C, Meulemans H, Moran MB, De Muynck A. A randomised trial of the impact of counselling on treatment adherence of tuberculosis patients in Sialkot, Pakistan. Int J Tuberc Lung Dis 1999; 3:1073-80.

46. Morrone N, Solha MS, Cruvinel MC, Morrono Junior N, Freire JAS, Barbosa ZLM. Tuberculose: tratamento supervisionado "versus" tratamento auto-administrado. J Pneumol 1999; 25:198-206. 
47. Liam CK, Lim KH, Wong CM, Tang BG. Attitudes and knowledge of newly diagnosed tuberculosis patients regarding the disease, and factors affecting treatment compliance. Int J Tuberc Lung Dis 1999; 3:300-9.

48. Borgdorff MW, Veen J, Kalisvaart NA, Broekmans JF, Nagelkerke NJ. Defaulting from tuberculosis treatment in The Netherlands: rates, risk factors and trend in the period 1993-1997. Eur Respir J 2000; 16:209-13.

49. Al-Hajjaj MS, Al-Khatim IM. High rate of noncompliance with anti-tuberculosis treatment despite a retrieval system: a call for implementation of directly observed therapy in Saudi Arabia. Int J Tuberc Lung Dis 2000; 4:345-9.

50. Ribeiro SA, Amado VM, Camelier AA, Fernandes MMA, Schenkman S. Estudo caso-controle de indicadores de abandono em doentes com tuberculose. J Pneumol 2000; 26:291-6.

51. Piyaworawong S, Yanai H, Nedsuwan S, Akarasewi P, Moolphate S, Sawanpanyalert P. Tuberculosis preventative therapy as part of a care package for people living with HIV in a district of Thailand. AIDS 2001; 15:1739-41.

52. Chaisson RE, Barnes GL, Hackman J, Watkinson L, Kimbrough L, Metha S, et al. A randomized, controlled trial of interventions to improve adherence to isoniazid therapy to prevent tuberculosis in injection drug users. Am J Med 2001; 110:610-5.

53. Escobar AL, Coimbra Jr. CEA, Camacho LA, Portela MC. Tuberculose em populações indígenas de Rondônia, Amazônia, Brasil. Cad Saúde Pública 2001; 17:285-98.

54. Hoz KF, Fernández S, Ordobás M, Gomez P, Fernandéz M, Arce A. Cumplimiento del tratamiento antituberculoso en presos excarcelados en la comunidad de Madrid. Enferm Infecc Microbiol Clin 2001; 19:362-6

55. Liefooghe R, Muynck AD. The dynamics of tuberculosis treatment adherence. J Pak Med Assoc 2001; 51:3-9.

56. Morisky DE, Malotte CK, Ebin V, Davidson P, Cabrera D, Trout PT, et al. Behavioral interventions for the control of tuberculosis among adolescents. Public Health Rep 2001; 116:568-74.

57. Naing NN, D'Este C, Isa AR, Salleh R, Bakar N, Mahmod MR. Factors contributing to poor compliance with anti-TB treatment among tuberculosis patients. Southeast Asian J Trop Med Public Health 2001; 32:369-82.

58. White MC, Tulsky JP, Goldenson J, Portillo CJ, Kawamura M, Menendez E. Randomized controlled trial of interventions to improve follow-up for latent tuberculosis infection after release from jail. Arch Intern Med 2002; 162:1044-50.
59. Rabahi MF, Rodrigues AB, Mello FQ, Almeida Netto JC, Kritski AL. Noncompliance with tuberculosis treatment by patients at a tuberculosis and AIDS reference hospital in midwestern Brazil. Braz J Infect Dis 2002; 6:63-73.

60. Tekle B, Mariam DH, Ali A. Defaulting from DOTS and its determinants in three districts of Arsi Zone in Ethiopia. Int J Tuberc Lung Dis 2002; 6:573-9.

61. O'Boyle SJ, Power JJ, Ibrahim MY, Watson JP. Factors affecting patient compliance with anti-tuberculosis chemotherapy using the directly observed treatment, short-course strategy (DOTS). Int J Tuberc Lung Dis 2002; 6:307-12.

62. Hovell MF, Sipan CL, Blumberg EJ, Hofstetter CR, Slymen D, Friedman L, et al. Increasing Latino adolescents' adherence to treatment for latent tuberculosis infection: a controlled trial. Am J Public Health 2003; 93:1871-7.

63. Nyirenda TE, Harries AD, Gausi F, van Gorkom J, Maher D, Floyd K, et al. Decentralisation of tuberculosis services in an urban setting, Lilongwe, Malawi. Int J Tuberc Lung Dis 2003; 7(9 Suppl 1): S21-8.

64. Buu TN, Lonnroth K, Quy HT. Initial defaulting in the National Tuberculosis Programme in Ho Chi Minh City, Vietnam: a survey of extent, reasons and alternative actions taken following default. Int J Tuberc Lung Dis 2003; 7:735-41.

65. El-Sony AI, Mustafa SA, Khamis AH, Enarson DA, Baraka OZ, Bjune G. The effect of decentralisation on tuberculosis services in three states of Sudan. Int J Tuberc Lung Dis 2003; 7:445-50.

66. Alvarez-Gordillo GDC, Alvarez-Gordillo JF, Dorantes-Jiménez JE. Estrategia educativa para incrementar el cumplimiento del régimen antituberculoso en Chiapas, México. Rev Panam Salud Pública 2003; 14:402-8.

67. Demissie M, Getahun H, Lindtjorn B. Community tuberculosis care through "TB clubs" in rural North Ethiopia. Soc Sci Med 2003; 56:2009-18.

68. Salami AK, Oluboyo PO. Management outcome of pulmonary tuberculosis: a nine year review in Ilorin. West Afr J Med 2003; 22:114-9.

69. Cayla JA, Caminero JA, Rey R, Lara N, Valles X, Galdos-Tanguis H. Current status of treatment completion and fatality among tuberculosis patients in Spain. Int J Tuberc Lung Dis 2004; 8:458-64.

Submitted on 12/Dec/2006

Final version resubmitted on 18/Dec/2007

Approved on 02/Jan/2008 